\title{
Deteksi Rhodamin B pada Saus Serta Cemaran Boraks dan Bakteri Salmonella sp. pada Cilok Jajanan Sekolah Dasar Kota Batam
}

\section{Detection of Rhodamin B in Sauce and Borax and Salmonella sp. Contaminants in Cilok Sold at Elementary Schools in Batam City}

\author{
Suci Fitriani Sammulia ${ }^{1 *}$, Netty Suhatri ${ }^{2}$, Hesti Chaterine Raja Guk-Guk ${ }^{1}$ \\ ${ }^{1}$ Prodi Sarjana Farmasi, Stikes Mitra Bunda Persada, Jalan Seraya No1 Teluk Tering, \\ Kota Batam, Kepulauan Riau 29441, Indonesia \\ ${ }^{2}$ Fakultas Farmasi, Universitas Andalas, Jalan Limau Manis, Kecamatan Pauh, \\ Kota Padang, Sumatera Barat 25163, Indonesia \\ *Corresponding author email: sucifitriani.sammulia22@gmail.com
}

Received 21-10-2019 Accepted 4-12-2019 Available online 30-12-2019

\begin{abstract}
ABSTRAK
Makanan Pedagang Kaki Lima (PKL) belum tersentuh pengawasan yang ketat oleh Badan Pengawas Obat dan Makanan (BPOM) sehingga secara kualitas tidak terpantau dengan baik sehingga perlu diwaspadai akan keamanan pangan seperti pada cilok, terutama pada jajanan Sekolah Dasar. Selain itu, cilok dijual dalam keadaan terbuka, sehingga memungkinkan terjadinya cemaran oleh mikroba. Tujuan penelitian ini sebagai sumber informasi ilmiah tentang deteksi rhodamin B dan boraks serta cemaran bakteri Salmonella sp. pada cilok di Sekolah Dasar. Penelitian ini merupakan penelitian eksperimen kualitatif dan kuantitatif. Hasil penelitian ini menunjukkan bahwa dari 5 sampel, 3 sampel (C, D, E) positif tercemar oleh Salmonella $s p$, untuk uji boraks dan rhodamin B menunjukkan bahwa kelima sampel negatif mengandung boraks dan rhodamin B, sehingga dapat disimpulkan dari kelima sampel yang paling aman untuk di komsumsi adalah cilok sampel A dan B.
\end{abstract}

Kata kunci: boraks, cilok, rhodamin B, Kota Batam, Salmonella sp.

\begin{abstract}
Street food vendors have not been monitored by the National Agency of Drug and Food Control (NADFC) properly and hence raise the concern on their safety. Cilok is commonly sold in elementary schools in a condition that possibly allowing microbial contamination to occur. The purpose of this study was to detect rhodamine $B$ and also borax and Salmonella sp. contaminants in cilok. This research was a qualitative and quantitative experimental study. The results of this study indicated that 3 of 5 samples $(C, D, E)$ were positively contaminated by Salmonella sp., while all samples were negative for the borax
\end{abstract}


and rhodamine $B$. It could be concluded that sample $A$ and $B$ were the safest to consume among 5 tested samples.

Key words: Batam city, borax, cilok, rhodamine B, Salmonella sp.

\section{Pendahuluan}

Undang-undang Nomor 7 Tahun

1996 menyatakan bahwa kualitas pangan yang dikonsumsi harus memenuhi beberapa kriteria, di antaranya adalah aman, bergizi, bermutu, dan dapat dijangkau oleh daya beli masyarakat. Aman maksudnya mencakup bebas dari cemaran biologis, mikrobiologi, kimia, logam berat, dan cemaran lain yang dapat mengganggu, merugikan, dan membahayakan kesehatan manusia (Mudjajanto, 2014).

Penggunaan Bahan Tambahan Pangan (BTP) harus sesuai dengan aturan perundang-undangan yang telah ditetapkan. Penambahan bahan tambahan pada makanan memiliki dosis tertentu karena bahan tambahan makanan dapat menyebabkan bahaya bagi kesehatan. Peran BTP menjadi semakin penting sejalan dengan kemajuan teknologi produksi bahan tambahan pangan sintetis (Prasetya dan Dewi, 2016).

Cilok adalah makanan ringan berbentuk bulat yang terbuat dari tepung kanji, berasa gurih, dan kenyal. Makanan ini sering dijual pada jajanan Sekolah Dasar. Harganya yang murah dan rasanya yang disukai anak-anak membuat jajanan ini laris manis. Hal inilah yang membuat para pedagang ramai-ramai menggunakan BTP mulai dari yang alami hingga bahan kimia yang dilarang penggunaannya seperti boraks. Hal ini bertujuan untuk mencegah cilok menjadi rusak dan cepat basi (Prasetya dan Dewi, 2016).

Boraks adalah salah satu bahan pengawet yang sering digunakan di Indonesia. Boraks merupakan suatu senyawa yang berbentuk kristal dengan warna putih dan tidak berbau serta sangat beracun, sehingga pemerintah mengeluarkan peraturan menteri kesehatan RI No. 772/Menkes/Per/IX/88 dan No. 1168/Menkes/Per/X 1999 (Prasetya dan Dewi, 2016).

Bahaya utama terhadap
kesehatan adalah iritasi saluran
pernapasan, kulit, dan mata. Pada dosis yang besar dapat menyebabkan takikardia, eritmia, kejang-kejang, dan koma. Kematian telah dilaporkan terjadi pada orang dewasa dengan dosis 5-20 g/kg BB. Karena efeknya berbahaya bagi kesehatan, maka pemerintah mengeluarkan peraturan larangan penggunaan boraks sebagi bahan tambahan pangan pada Peraturan Mentri Kesehatan RI No.003/Menkes/Per/2012 tentang BTP mengatakan bahwa boraks termaksuk Bahan yang Berbahaya dan Beracun (B3) sehingga tidak boleh digunakan sebagai bahan tambahan makanan (Silalahi, 2010).

Dalam penyajiannya, cilok diberi saus untuk memberikan cita rasa. Akan 
tetapi ternyata masih ada produsen yang sengaja menambahkan zat warna rhodamin B sebagai pewarna merah pada saus. Menurut Standar Nasional Indonesia (2004) rhodamin B merupakan zat warna sintetik yang umum digunakan sebagai pewarna tekstil namun dilarang penggunaannya dalam produk-produk pangan. Rhodamin B dapat menyebabkan iritasi saluran pernafasan, iritasi kulit, iritasi pada mata, iritasi pada saluran pencernaan, keracunan, dan gangguan hati (Prasetya dan Dewi, 2016).

Cilok tergolong dalam kategori makanan pedagang kaki lima (PKL). Makanan PKL belum tersentuh pengawasan yang ketat oleh Badan Pengawas Obat dan Makanan (BPOM) sehingga secara kualitas tidak terpantau dengan baik, sehingga perlu diwaspadai akan keamanan pangan dari cilok tersebut, terutama pada jajanan sekolah dasar. Selain itu, cilok dijual dalam keadaan terbuka dan dibiarkan dalam waktu yang lama, sehingga memungkinkan terjadinya cemaran oleh mikroba. Bakteri Salmonella sp. sering dijadikan standar utama kebersihan pangan, karena mengindikasikan adanya cemaran-cemaran bakteri lain yang berpotensi menyebabkan penyakit (Prasetya dan Dewi, 2016).

Berdasarkan latar belakang tersebut, maka perlu dilakukan deteksi bakteri Salmonella sp. dan boraks pada cilok serta rhodamin b pada saus yang dijual di beberapa sekolah dasar Kota Batam. Penelitian ini bertujuan untuk mengetahui adakah kandungan boraks dan rhodamin B dan apakah cemaran bakteri Salmonella sp memenuhi syarat batas cemaran mikroba.

\section{Metode Penelitian}

Penelitian ini dilaksanakan pada bulan Februari sampai April 2018. Penelitian dilakukan di Laboratorium Kimia Farmasi Analisis dan Laboratorium Mikrobiologi, Program Studi Sarjana Farmasi, Sekolah Tinggi IImu Kesehatan Mitra Bunda Persada Batam.

Alat dan Bahan

Alat-alat yang digunakan antara lain: LAF (Laminar Air Flow), hot plate, magnetic stirrer, mikroskop, alat ukur gelas, lampu spiritus, buret, batang pengaduk, lampu UV $254 \mathrm{~nm}$, plat Kromatografi Lapis Tipis (KLT), dan TLC Silica gel 60. Sedangkan Bahan-bahan yang digunakan antara lain: sampel cilok $(A, B, C, D, E)$, boraks, rhodamin $B$, saus cabai, $\mathrm{NaCl}$ fisiologis 0,9\%, asam klorida $4 \mathrm{M}$ (Merck), perak nitrat 0,1 N (Merck), barium klorida 0,1 N (Merck), etanol $70 \%$, etanol $96 \%$ (Merck), metanol (Merck), asam sulfat (pekat) (Merck), amonia (Merck), isopropanol (Merck), media Salmonella Shigella Agar (SSA), minyak immersi, lugol, gentian violet, safranin, kunyit, dan akuades.

Pengambilan Sampel

Pengambilan sampel pada penelitian ini dilakukan berdasarkan ada tidaknya penjual cilok keliling di Sekolah Dasar di Kota Batam, serta menggunakan metode purposive sampling. Sampel yang digunakan dalam penelitian ini diambil secara acak di 5 penjual jajanan 
cilok di sekolah dasar yang berbedabeda lokasinya.

\section{Uji Kandungan Boraks}

1. Prosedur penyiapan sampel

Sampel cilok dipotong kecil-kecil kemudian dihaluskan sampai halus dengan menggunakan mortar dan stamfer, ditimbang sebanyak $5 \mathrm{~g}$. Sampel dimasukkan dalam gelas piala $50 \mathrm{ml}$ lalu ditambahkan akuades 10 $\mathrm{ml}$, direndam hingga 24 jam. Sampel yang telah halus lalu disaring menggunakan kertas saring, diambil filtratnya, dan dimasukkan ke dalam gelas piala $50 \mathrm{ml}$ yang kosong untuk diidentifikasi dengan metode analisis kualitatif.

2. Analisis kualitatif

\section{Uji tumerik}

Kunyit segar diparut sebanyak 200 g kemudian disaring dan diambil airnya dan dimasukkan ke dalam kaca arloji. Selanjutnya kertas saring di celupkan kemudian dibolak-balik hingga merata pada seluruh permukaan kertas saring. Kertas saring dikeringkan di bawah terik matahari hingga kering. Setelah kertas kering diteteskan 2 tetes untuk masing-masing sampel $(A, B, C, D, E)$ ke atas kertas kunyit, kemudian diamati perubahan yang terjadi. Jika mengandung boraks maka kertas tumerik akan berubah warna menjadi merah kecoklatan (Fuad, 2014).

\section{Uji dengan larutan perak nitrat}

Filtrat dari masing-masing sampel (A, B, C, D, E) sebanyak $1 \mathrm{ml}$ kemudian dimasukkan ke dalam tabung reaksi, lalu ditambahkan larutan perak nitrat sebanyak $5 \mathrm{ml}$. Perubahan yang terjadi diamati, jika terdapat endapan putih maka sampel dikatakan positif mengandung boraks (Efrilia et al., 2016).

\section{Uji dengan larutan barium klorida}

Filtrat dari masing-masing sampel (A, B, C, D, E) diambil sebanyak $1 \mathrm{ml}$, kemudian dimasukkan ke dalam tabung reaksi, lalu ditambahkan larutan barium klorida sebanyak $5 \mathrm{ml}$. Perubahan yang terjadi diamati, jika terdapat endapan putih maka sampel dikatakan positif mengandung boraks (Efrilia et al., 2016).

Uji nyala api dengan menggunakan asam sulfat (pekat) dan mentol

Masing-masing sampel (A, B, C, D, E) ditimbang sebanyak $5 \mathrm{~g}$, ditambahkan $10 \mathrm{ml}$ akuades, kemudian diblender hingga halus. Sampel yang telah halus, disaring dan diambil filtratnya, dimasukkan ke dalam cawan porselin, ditambahkan 1 $\mathrm{ml}$ asam sulfat (pekat), ditambahkan metanol sebanyak $5 \mathrm{ml}$, kemudian dihomogenkan. Sampel diberi nyala api (dengan korek api), jika nyala api berwarna hijau maka sampel dikatakan positif mengandung boraks (Prasetya dan Dewi, 2016).

3. Uji kandungan rhodamin $B$

Masing-masing sampel saus cabai (A, B, C, D, E) diambil sebanyak $5 \mathrm{ml}$, dimasukkan ke dalam gelas ukur $10 \mathrm{ml}$. Kemudian diambil etanol $70 \%$ sebanyak $10 \mathrm{ml}$ untuk masing-masing sampel saus cabai tersebut. Sampel A dimasukkan dalam gelas piala $50 \mathrm{ml}$, 
dilarutkan dengan menggunakan etanol $70 \%$ sebanyak $10 \mathrm{ml}$, disaring dan diambil filtratnya, begitu pula pengerjaan seterusnya untuk sampel B, C, D, dan E. Sampel ditotolkan sebanyak $2 \mu \mathrm{l}$ pada plat KLT untuk sampel saus dan rhodamin $B$, dimasukkan ke dalam bejana dan ditutup kembali bejananya. Fase gerak yang digunakan adalah isopropanol : amonia $=100: 25(\mathrm{v} / \mathrm{v})$, dan fase diamnya plat KLT silika gel dengan lebar $2 \mathrm{~cm}$ dan panjang 10 $\mathrm{cm}$. elusi diamati hingga naik sampai tanda batas. Apabila sudah sampai tanda batas, plat KLT diangkat, diamati di bawah sinar ultraviolet 254 $\mathrm{nm}$, dan dihitung nilai Rf masingmasing sampel antara $2-7 \mathrm{~cm}$ (Agustin et al., 2016).

4. Deteksi cemaran Salmonella sp

Sampel cilok $500 \mathrm{mg}$ ditimbang, ditambahkan akuades $10 \mathrm{ml}$, kemudian diblender sampai halus dan homogen. Sampel disaring, dimasukkan ke dalam gelas piala, ditambahkan $2 \mathrm{ml} \mathrm{NaCl}$ fisiologis, kemudian diaduk sampai terbentuk suspensi. Larutan suspensi diambil sebanyak 0,2 $\mathrm{ml}$, dimasukkan ke dalam cawan petri yang berisi media SSA yang sudah diratakan menggunakan swips batang. Perlakuan sampel direplikasi sebanyak dua kali pengulangan. Media diinkubasi pada suhu 37 ㅇ selama 24-48 jam, kemudian diamati perubahan yang terjadi. Deteksi cemaran bakteri Salmonella sp dapat dilihat dari ada atau tidaknya pertumbuhan bakteri tersebut pada medium spesifik. Jika sampel diduga mengandung Salmonella sp maka akan terbentuk koloni yang tidak berwarna dengan inti hitam besar di tengah (Prasetya dan Dewi, 2016).

5. Analisis data

Analisis data dilakukan secara deskriptif terhadap ada tidaknya kandungan Salmonella sp, boraks, dan rhodamin B yang diperoleh dan dibuat dalam bentuk tabel dan dinarasikan pada hasil dan pembahasan serta diambil kesimpulan.

\section{Hasil dan Pembahasan}

Uji Kandungan Boraks pada Cilok

Hasil pengujian boraks dengan menggunakan sampel cilok dari SD A, B, C, D, dan E yang dilakukan pada pengujian uji nyala api, uji tumerik, uji barium klorida dan uji perak nitrat diperoleh hasil negatif tidak mengandung boraks. Hasil tersebut ditunjukkan pada Tabel 1.

Uji identifikasi boraks dilakukan secara kualitatif pada sampel cilok. Cilok dipilih pada penelitian ini karena cilok tidak memiliki izin registrasi BPOM dan dibuat sendiri oleh pedagang. Sampel yang digunakan sebanyak 5 sampel dangan dilakukannya tiga kali pengulangan di hari yang berbeda. Hasil pengujian uji nyala api menunjukkan bahwa 5 sampel tersebut tidak mengandung boraks.

Untuk sampel kontrol yang mengandung boraks, setelah dilakukan uji nyala api, berwarna hijau yang 
disebabkan oleh terbentuknya metil $\mathrm{B}\left(\mathrm{OC}_{2} \mathrm{H}_{5}\right)_{3} \cdot\left({ }_{18}\right)$ Reaksi yang terjadi dapat borat $\mathrm{B}\left(\mathrm{OCH}_{3}\right)_{3}$ atau etil borat dilihat pada Persamaan reaksi 1.

$$
\mathrm{H}_{3} \mathrm{BO}_{3}+3 \mathrm{CH}_{3} \mathrm{OH} \rightarrow \mathrm{B}\left(\mathrm{OCH}_{3}\right)_{3} \uparrow+3 \mathrm{H}_{2} \mathrm{O}
$$

Hasil pengujian warna dengan kertas tumerik menunjukkan bahwa sampel cilok tidak mengandung boraks, sampel kontrol yang mengandung boraks setelah dilakukan uji dengan kertas tumerik akan berwarna coklat kemerahan (Fuad, 2014).

Hasil pengujian warna dengan $\mathrm{AgNO}_{3}$ menunjukkan bahwa semua sampel cilok tidak mengandung boraks. Untuk sampel kontrol yang mengandung boraks setelah uji warna dengan $\mathrm{AgNO}_{3}$ akan menghasilkan endapan putih perak metaborat $\mathrm{AgBO}_{2}$ dari larutan boraks yang cukup pekat yang larut baik dalam larutan amonia encer maupun dalam asam asetat.

Tabel 1. Hasil uji tumerik, $\mathrm{AgNO}_{2}, \mathrm{BaCl}_{2}$, dan nyala api

\begin{tabular}{|c|c|c|c|c|c|}
\hline \multirow{2}{*}{ No } & \multirow{2}{*}{ Sampel Cilok } & \multirow{2}{*}{ Uji Nyala Api } & \multicolumn{3}{|c|}{ Pengujian Reaksi Warna } \\
\hline & & & Tumerik & Barium Klorida & Perak Nitrat \\
\hline \multirow[t]{3}{*}{1} & Boraks (Kontrol) & 1. + & 1. + & 1. + & 1. + \\
\hline & & 2. + & 2. + & 2. + & 2. + \\
\hline & & 3. + & 3. + & 3. + & 3. + \\
\hline \multirow[t]{3}{*}{2} & SD A & 1. - & 1. - & 1. - & 1. - \\
\hline & & 2. - & 2. - & 2. - & 2. - \\
\hline & & 3. - & 3. - & 3. - & 3. - \\
\hline \multirow[t]{3}{*}{3} & SD B & 1. - & 1. - & 1. - & 1. - \\
\hline & & 2. - & 2. - & 2. - & 2. - \\
\hline & & 3. - & 3. - & 3. - & 3. - \\
\hline \multirow[t]{3}{*}{4} & SD C & 1. - & 1. - & 1. - & 1. - \\
\hline & & 2. - & 2. & 2. - & 2. - \\
\hline & & 3. - & 3. - & 3. - & 3. - \\
\hline \multirow[t]{3}{*}{5} & SD D & 1. - & 1. & 1. - & 1. - \\
\hline & & 2. - & 2. & 2. - & 2. - \\
\hline & & 3. - & 3. & 3. - & 3. - \\
\hline \multirow[t]{3}{*}{6} & SD E & 1. - & 1. & 1. - & 1. - \\
\hline & & 2. - & 2. - & 2. - & 2. - \\
\hline & & 3. - & 3. - & 3. - & 3. - \\
\hline
\end{tabular}

Keterangan: tanda (+) positif mengandung boraks, tanda (-) negatif mengandung boraks.

Reaksi yang terjadi dapat dilihat pada Persamaan reaksi 2. Endapan terjadi dikarenakan oleh adanya reaksi antara $\mathrm{Ag}^{+}$dengan ion $\mathrm{Cl}^{-}$sehingga menghasilkan senyawa $\mathrm{AgCl}$ yang menghasilkan endapan putih. Hasil 
pengujian warna dengan $\mathrm{BaCl}_{2}$ metaborat, $\mathrm{Ba}\left(\mathrm{BO}_{2}\right)_{2}$, dari larutan-larutan menunjukkan bahwa semua sampel cilok yang cukup pekat, endapan larutan tidak mengandung boraks. Untuk sampel dalam regensia berlebih dalam asamkontrol yang mengandung boraks asam encer dan dalam larutan garamsetelah uji warna dengan $\mathrm{BaCl}_{2}$ akan menghasilkan endapan putih barium garam ammonium. Reaksi yang terjadi seperti pada Persamaan reaksi 3.

$$
\begin{aligned}
& \mathrm{B}_{4} \mathrm{O}_{7}^{2-}+4 \mathrm{Ag}^{+}+\mathrm{H}_{2} \mathrm{O} \rightarrow 4 \mathrm{AgBO}_{2} \downarrow+2 \mathrm{H}^{+} \\
& \mathrm{B}_{4} \mathrm{O}_{7}^{2-}+2 \mathrm{Ba}^{2+}+\mathrm{H}_{2} \mathrm{O} \rightarrow 2 \mathrm{Ba}\left(\mathrm{BO}_{2}\right)_{2} \downarrow+2 \mathrm{H}^{+}
\end{aligned}
$$

\begin{tabular}{|c|c|c|c|c|c|c|c|}
\hline \multicolumn{2}{|c|}{ Rhodamin B } & \multicolumn{2}{|c|}{ Saus } & \multirow{2}{*}{$\begin{array}{c}\text { UV } \\
254 \mathrm{~nm}\end{array}$} & \multirow{2}{*}{$\mathrm{HCl}(4 \mathrm{M})$} & \multirow{2}{*}{$\begin{array}{c}\mathrm{H}_{2} \mathrm{SO}_{4} \\
\text { (Pekat) }\end{array}$} & \multirow{2}{*}{ Kesimpulan } \\
\hline Warna & Rf & Sampel & Rf & & & & \\
\hline $\begin{array}{l}\text { Merah } \\
\text { jingga }\end{array}$ & $\begin{array}{l}\text { 1. } 0,78 \\
\text { 2. } 0,8 \\
\text { 3. } 0,837\end{array}$ & SD A & $\begin{array}{l}\text { 1. } 0,7 \\
\text { 2. } 0,7 \\
\text { 3. } 0,7\end{array}$ & $\begin{array}{c}\text { Merah } \\
\text { bata }\end{array}$ & $\begin{array}{c}\text { Merah } \\
\text { bata }\end{array}$ & $\begin{array}{c}\text { Merah } \\
\text { bata }\end{array}$ & Negatif \\
\hline $\begin{array}{l}\text { Merah } \\
\text { jingga }\end{array}$ & $\begin{array}{l}\text { 1. } 0,7 \\
\text { 2. } 0,77 \\
\text { 3. } 0,75\end{array}$ & SD B & $\begin{array}{l}\text { 1. } 0,56 \\
\text { 2. } 0,6 \\
\text { 3. } 0,6\end{array}$ & $\begin{array}{c}\text { Merah } \\
\text { bata }\end{array}$ & $\begin{array}{c}\text { Merah } \\
\text { bata }\end{array}$ & $\begin{array}{c}\text { Merah } \\
\text { bata }\end{array}$ & Negatif \\
\hline $\begin{array}{l}\text { Merah } \\
\text { jingga }\end{array}$ & $\begin{array}{l}\text { 1. } 0,76 \\
\text { 2. } 0,77 \\
\text { 3. } 0,75\end{array}$ & SD C & $\begin{array}{l}\text { 1. } 0,6 \\
\text { 2. } 0,61 \\
\text { 3. } 0,6\end{array}$ & $\begin{array}{c}\text { Merah } \\
\text { bata }\end{array}$ & $\begin{array}{c}\text { Merah } \\
\text { bata }\end{array}$ & $\begin{array}{c}\text { Merah } \\
\text { bata }\end{array}$ & Negatif \\
\hline $\begin{array}{l}\text { Merah } \\
\text { jingga }\end{array}$ & $\begin{array}{l}\text { 1. } 0,775 \\
\text { 2. } 0,775 \\
\text { 3. } 0,8\end{array}$ & SD D & $\begin{array}{l}\text { 1. } 0,68 \\
\text { 2. } 0,7 \\
\text { 3. } 0,7\end{array}$ & $\begin{array}{c}\text { Merah } \\
\text { bata }\end{array}$ & $\begin{array}{c}\text { Merah } \\
\text { bata }\end{array}$ & $\begin{array}{c}\text { Merah } \\
\text { bata }\end{array}$ & Negatif \\
\hline $\begin{array}{l}\text { Merah } \\
\text { jingga }\end{array}$ & $\begin{array}{l}\text { 1. } 0,75 \\
\text { 2. } 0,76 \\
\text { 3. } 0,762\end{array}$ & SD E & $\begin{array}{l}\text { 1. } 0,662 \\
\text { 2. } 0,65 \\
\text { 3. } 0,65\end{array}$ & $\begin{array}{c}\text { Merah } \\
\text { bata }\end{array}$ & $\begin{array}{c}\text { Merah } \\
\text { bata }\end{array}$ & $\begin{array}{c}\text { Merah } \\
\text { bata }\end{array}$ & Negatif \\
\hline
\end{tabular}

Tabel 2. Hasil uji rhodamin B menggunakan plat KLT

Uji Kandungan Rhodamin B pada Saus Cabai

Analisis rhodamin B pada saus dengan metode KLT menunjukkan semua sampel hasilnya negatif. Sampel yang digunakan sebanyak 5 sampel dangan dilakukannya tiga kali penggulangan di hari yang berbeda. Hasil analisis berdasarkan nilai $\mathrm{Rf}$ masingmasing sampel dibandingkan dengan $\mathrm{Rf}$ standar rhodamin B tidak menunjukkan nilai $\mathrm{Rf}$ yang sama ataupun mendekati dan tidak menunjukkan warna merah jingga ketika direaksikan dengan $\mathrm{HCl}$ dan $\mathrm{H}_{2} \mathrm{SO}_{4}$ (Tabel 2). Hasil pengujian rhodamin $B$ dengan menggunakan sampel saus cabai dari SD A, B, C, D, E yang dilakukan pada pengujian menggunakan plat KLT diperoleh hasil negatif tidak mengandung rhodamin $\mathrm{B}$. 
Deteksi Cemaran Bakteri Salmonella sp

Hasil pengujian deteksi cemaran

Salmonella sp. dengan menggunakan sampel cilok dari SD A, B, C, D, E yang dilakukan pada pengujian dengan menggunakan media SSA (Salmonella
Shigella Agar) diperoleh hasil sampel A dan $B$ negatif tidak mengandung Salmonella sp, dan untuk sampel C, D, E diperoleh hasil positif mengandung Salmonella sp sesuai dengan yang disajikan oleh Gambar 1.
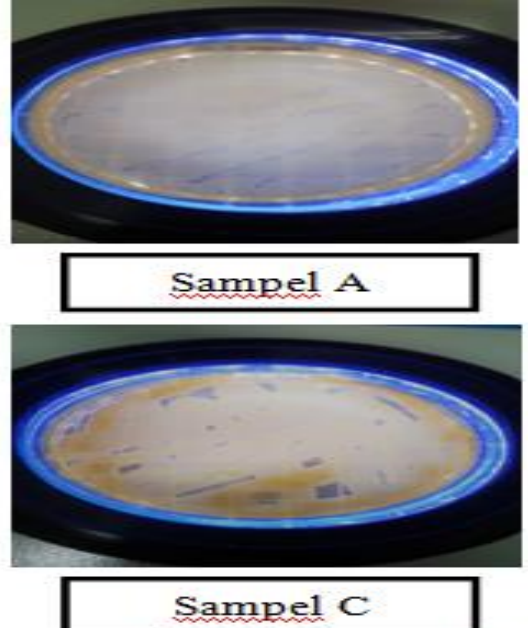

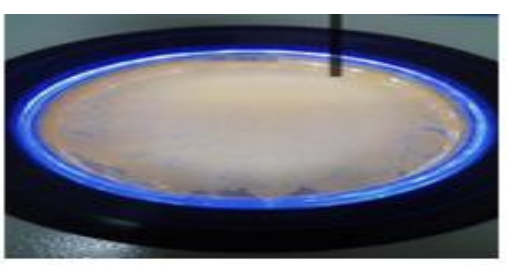

Sampe1 B
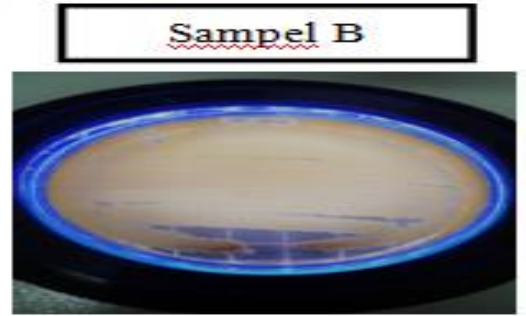

Sampe1 D

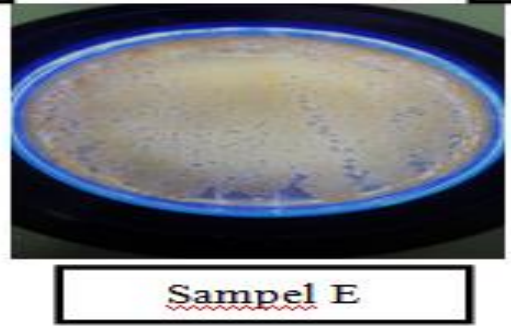

Gambar 1. Hasil pengujian cilok dengan media SSA.

Berdasarkan hasil isolasi dari media SSA dan sampel yang digunakan sebanyak 5 sampel dangan dilakukannya dua kali penggulangan di hari yang sama, didapat 3 sampel yang positif mengandung bakteri Salmonella sp. yang ditunjukkan dengan terbentuknya koloni hitam pada bagian media karena Salmonella sp. dapat menghasilkan $\mathrm{H}_{2} \mathrm{~S}$ yang akan menghasilkan endapan hitam pada media SSA. Media SSA memiliki kandungan besi ammonium sitrat yang bereaksi dengan $\mathrm{H}_{2} \mathrm{~S}$ yang menghasilkan endapan hitam pada pusat koloni (BPOM, 2016).

Menurut Badan Pengawas Obat dan Makanan (BPOM) Republik Indonesia (2016), kandungan Salmonella sp yaitu negatif per 25 mg makanan (Yolanda, 2014). Sedangkan pada sampel penelitian ditemukan 3 sampel yang mengandung bakteri patogen yaitu 
Salmonella sp sehingga makanan ini dapat menimbulkan bahaya pada tubuh manusia. Hal ini berdasarkan penelitian yang dilakukan oleh Yolanda di Manado pada makanan jajanan yaitu bakso tusuk yang dijual di kota Manado (Yolanda, 2014).

Dari 20 sampel bakso tusuk didapatkan 9 sampel mengandung bakteri Salmonella sp (Andreano, 2015). Makanan yang mengandung bakteri seperti Salmonella sp dalam jumlah kecil tidak akan merubah bentuk warna, rasa dan bau dari makanan tersebut. Namun apabila makanan tersebut mengandung bakteri dalam jumlah yang banyak akan membuat perubahan bentuk, rasa, dan bau yang khas yang ditimbulkan dari bakteri. Pada sampel penelitian ini, tidak terdapat perubahan bentuk, rasa, dan bau yang khas dari sampel cilok yang diuji, jadi kemungkinan jumlah bakteri Salmonella sp yang terbentuk di dalamnya masih dalam jumlah yang sedikit. Hasil penelitian oleh Yolanda 2014 sesuai dengan penelitian ini bahwa pada makanan jajanan ditemukan Salmonella sp. Terdapat 2 sampel cilok yang tidak terdapat kontaminasi Salmonella sp, ini dibuktikan bahwa tidak ada pertumbuhan koloni Salmonella sp pada media SSA. Hal ini disebabkan bakteri Salmonella sp sudah mati karena proses pengelolaannya dilakukan pada suhu yang tinggi sehingga Salmonella sp tidak dapat tumbuh. Selain itu kemungkinan bakteri yang terdapat pada sampel tersebut bukanlah bakteri Salmonella sp ataupun Shigella sp sehingga tidak dapat tumbuh pada media SSA yang merupakan media selektif untuk bakteri Salmonella sp dan Shigella sp. Hal ini sesuai dengan penelitian sebelumnya mengenai identifikasi bakteri aerob pada jagung bakar yang dilakukan di Kota Manado. Pada penelitian tersebut tidak ditemukan bakteri Salmonella sp pada seluruh sampelnya melainkan bakteri lain (Andreano, 2015).

\section{Simpulan}

Dari kelima sampel cilok yang telah dilakukan uji kualitatif kandungan rhodamin B dan boraks menunjukkan hasil yang negatif sehingga aman untuk dikonsumsi, akan tetapi pada pengujian cemaran bakteri Salmonella $\mathrm{sp}$ menggunakan media SSA, ada 3 sampel yang tercemar yaitu sampel $C, D$, dan $E$.

\section{Ucapan Terima Kasih}

Terima kasih kepada seluruh civitas akademik Stikes Mitra Bunda Persada Batam khususnya Program Studi Sarjana Farmasi atas dukungan dan supportnya terhadap penelitian ini.

\section{Daftar Pustaka}

Agustin, N.C., Sulistyarsi, A., Utami, S. 2016. Analisis rhodamin B pada saus tomat yang beredar di Kota Madiun dengan metode kromatografi lapis tipis. Jurnal Florea, (3):65-71.

Andreano. 2015. Identifikasi bakteri aerob pada jagung bakar. Skripsi. Fakultas Kedokteran, Universitas Sam Ratulagi. 
Badan Pengawas Obat dan Makanan. 2016. Peraturan Kepala Badan Pengawasan Obat dan Makanan Republik Indonesia Nomor 16. tentang Penetapan Batas Cemaran Mikroba dan Kimia pada Makanan.

Efrilia, M., Prayoga, T., Mekasari, N. 2016. Identifikasi boraks dalam bakso di Kelurahan Bahagia, Bekasi Utara, Jawa Barat dengan metode analisa kualitatif. Jurnal IImiah Ibnu Sina, (1):113-120.

Fuad, N. 2014. Identifikasi kandungan boraks pada tahu pasar tradisional di daerah Ciputat. Skripsi. Fakultas Kedokteran dan Ilmu Kesehatan, Universitas Indonesia.

Mudjajanto, E.S. 2006. Tahu, makanan favorit yang keamanannya perlu diwaspadai.

http://www.Kompas.com/keseh atan/News/0503/30/101104.ht m. Data diakses pada 2 Maret 2019.
Prasetya, A.W. dan Dewi, L. 2016. Deteksi kandungan rhodamin B pada saus serta cemaran boraks dan bakteri Salmonella sp pada cilok keliling Salatiga. Jurnal Agric Ilmu Pertanian, 28(1-2):6978.

Silalahi, J. 2010. Pemeriksaan boraks di dalam bakso di Kota Medan. Majalah kedokteran Indonesia, 60(11):11-18.

Standar Nasional Indonesia. 2004. Saus Tomat. Jakarta: Badan Standarisasi Nasional.

Susilawati, A. 2002. Keamanan mikrobiologi dan survei di pasar tradisional di daerah Bogor. Skripsi. Fakultas Teknologi Pertanian, Institusi Pertanian Bogor.

Yolanda, A. 2014. Identifikasi bakteri Escherichia coli dan Salmonella sp pada jajanan bakso tusuk di Kota Manado. Skripsi. Fakultas Kedokteran, Universitas Sam Ratulagi Manado. 